\title{
Avaliação Clínica e Laboratorial de Crianças e Adolescentes com Queixas Vulvovaginais
}

\author{
Clinical and Laboratorial Evaluation of Children and Teenagers with Vulvovaginal Complaints
}

Miriam da Silva Wanderley, Edna Maria Salazar Magalhães, Érica Rosa Trindade

\section{RESUM0}

\begin{abstract}
Objetivo: analisar as queixas vulvovaginais mais freqüentemente observadas no Ambulatório de Ginecologia Infanto-Puberal (AGIP) do Hospital Universitário de Brasília (HUB).

Métodos: foram avaliados retrospectivamente 210 prontuários de meninas, até 18 anos de idade, que procuraram o AGIP/HUB com queixas vulvovaginais. Analisaram-se as queixas mais freqüentes e os agentes etiológicos mais observados à secreção vaginal.

Resultados: a idade média das 210 pacientes estudadas, até dezoito anos, foi de $12 \pm 2,3$ anos $e$ as queixas mais comuns foram o corrimento vaginal e o prurido vulvar. Alterações inflamatórias inespecíficas foram observadas em 147 destas pacientes (70\%) as quais foram tratadas com orientação a respeito de vestuário, de atividades diárias e de higiene. As outras 63 pacientes, nas quais foi observado um agente etiológico específico, necessitaram de tratamento medicamentoso apropriado. Somente em pacientes com vida sexual ativa foram observados infecções por Gardnerella vaginalis, Trichomoma vaginalis, HPV, assim como sifilis. Para estas pacientes a idade da sexarca foi de 14,1 $\pm 1,6$ anos. Vinte pacientes apresentaram queixas vulvares concomitantemente, de fácil manuseio e orientação.

Conclusão: higiene, vestuário e orientação adequada às pacientes e seus familiares são fundamentais para o controle e tratamento das queixas vulvovaginais, quase sempre dispensando o uso de antimicrobianos.
\end{abstract}

PALAVRAS-CHAVE: Infância e adolescência. HPV. Vulvovaginite. Sífilis.

\section{Introdução}

As queixas vulvovaginais na infância e adolescência são um motivo de constantes visitas ao médico, pediatra e/ou ginecologista, que, quase sempre despreparados para orientar estes casos, muitas vezes tomam condutas intempestivas prescrevendo medicamentos, freqüentemente antibióticos de largo espectro, sem necessidade.

Além da falta de preparo no atendimento destes casos, não há ainda um entendimento claro do complexo meio ambiente vaginal e de sua

Departamento de Ginecologia e Obstetrícia da Faculdade de Ciências da Saúde- Universidade de Brasília.

Correspondência:

Miriam da Silva Wanderley

Departamento Ginecologia e Obstetrícia, Faculdade de

Ciências da Saúde, Universidade de Brasília

Caixa Postal: 4360

70919- 970 - Brasilia - DF

Fone: (61) 273-4069/ fax: (61) 245-3676

e-mail: miriamsw@unb.br homeostase e das interrelações com os mecanismos de defesa do hospedeiro, que são distintos em meninas pré-púberes e naquelas que já menstru$\operatorname{aram}^{1,2}$.

A flora vaginal normal é predominantemente aeróbica, sendo que os lactobacilos produtores de peróxido de hidrogênio são as bactérias mais comumente observadas. Em mulheres no menacme o $\mathrm{pH}$ vaginal normal é menor que 4,5 devido à produção de ácido lático. Ao serem estimuladas pelo estrogênio, as células epiteliais vaginais, ricas em glicogênio, decompõe-no em monossacarídeos, que são convertidos em ácido lático pelos lactobacilos ${ }^{3,4}$.

Em meninas pré-púberes a presença de vagina atrófica não-estrogenizada, com $\mathrm{pH}$ de 6,5 a 7,5 , a ausência de coxins adiposos vulvares e de pelos pubianos, a curta distância entre a vagina e o ânus, a pequena abertura do hímen obstruindo a saída de secreções vaginais e a diminuição dos mecanismos imunes locais são fatores predispo- 
nentes para o aparecimento de vulvovaginites, cujos patógenos causais são geralmente distintos dos de uma mulher no menacme $e^{1,5}$. Também não se pode esquecer que muitas vezes pode estar envolvido um caso de abuso sexual, quase sempre negado pela família, ou de relações sexuais consentidas desconhecidas dos familiares, o que torna dificil a abordagem e o tratamento efetivo destas meninas.

Este trabalho tem por objetivo analisar os casos de vulvovaginite, suas queixas e agentes etiológicos mais freqüentes, em meninas até dezoito anos de idade.

\section{Pacientes e Métodos}

No período de janeiro de 1997 a dezembro de 1998, 453 pacientes procuraram o Ambulatório de Ginecologia Infanto-Puberal (AGIP) do Hospital Universitário de Brasília (HUB), que atende meninas até 18 anos de idade. Destas, 210 (46,3\%) referiram sinais e/ou sintomas vulvovaginais. Os prontuários destas 210 pacientes foram analisados retrospectivamente em relação à história clínica, exame fisico geral e ginecológico, no qual foi colhida secreção vaginal para exame a fresco e avaliação laboratorial por meio do Papanicolaou e bacterioscopia. Se as pacientes fossem sexualmente ativas o exame era colhido da forma habitual se não, por swab vaginal. Além disso, também foi realizado exame parasitológico de fezes e de urina (sumário e cultura) nas pacientes que apresentassem queixas clínicas sugestivas de infecção e/ou verminose.

Em relação à queixa clínica, foi avaliada a presença de corrimento vaginal com ou sem odor, prurido vulvar e dor pélvica. As características do corrimento vaginal observado associado ao achado de hifas, flagelados móveis e de clue cells à microscopia óptica foram diagnósticos de candidiase, tricomoniase e gardnerelose, respectivamente. Estabeleceu-se o diagnóstico de vulvovaginite inespecífica quando a análise da secreção vaginal revelou uma mistura de leucócitos (mais de 10/campo) e bactérias em grande quantidade ${ }^{6}$.

Nas pacientes que referiram promiscuidade sexual, parceiro tratado ou com doença sexualmente transmissivel (DST) ou que apresentassem lesões aceto- brancas ao teste do ácido acético 3\% ou condiloma acuminado ao exame foi solicitado VDRL, sorologia anti-HIV e/ou realizado colposcopia com biópsia dirigida da lesão genital para diagnóstico de papilomavirus humano (HPV). Também foram realizadas biópsias vulvoperineais em pacientes que apresentaram a região espessada, com placas esbranquiçadas e pruriginosas para diagnóstico definitivo e diferencial entre líquen escleroso e vitiligo vulvar.

\section{Resultados}

No período de janeiro de 1997 a dezembro de 1998, 210 pacientes com até 18 anos de idade (média de 12 $\pm 2,3$ anos) procuraram o AGIP/HUB (Tabela 1) referindo algum sinal e/ou sintoma de vulvovaginite. Destas, 20 também apresentaram queixas de alterações vulvares.

\begin{tabular}{ccc} 
Tabela 1- Prevalência de queixas vulvovaginais em relação à faixa etária. & \\
\hline Idade (anos) & $\mathbf{n}$ & $\%$ \\
\hline$\leq 2$ & 5 & 2,4 \\
$3-6$ & 29 & 13,8 \\
$7-10$ & 51 & 24,3 \\
$11-14$ & 73 & 34,7 \\
$15-18$ & 52 & 24,8 \\
Total & 210 & \\
\hline
\end{tabular}

As queixas mais freqüentemente referidas por estas pacientes, que foram corrimento vaginal com ou sem odor fétido, prurido e dor pélvica, podem ser observadas na Tabela 2. Além disso, observamos concomitantemente queixas urinárias como disúria e polaciúria em 13 pacientes, sendo confirmada infecção do trato urinário em exame específico e cultura adequadamente colhidos. Em 27 pacientes foi observado algum tipo de verminose ao exame parasitológico de fezes, no qual a ascaridiase foi o mais comum $(\mathrm{n}=11)$, seguido pela oxiuriase (9), giardiase (5) e amebiase (2). A análise concomitante da secreção vaginal revelou 19 casos de secreção inespecífica, 7 de cocos sp e 1 de cândida sp.

Tabela 2 - Queixas ginecológicas que motivaram as pacientes a procurarem o Ambulatório de Ginecologia Infanto-Puberal do Hospital da Universidade de Brasília

\begin{tabular}{lrc}
\hline Queixas Clínicas & $\mathbf{n}$ & $\%$ \\
\hline Corrimento vaginal exclusivo & 86 & 40,9 \\
Corrimento vaginal + odor fétido na região genital & 48 & 22,8 \\
Corrimento vaginal + prurido vulvar & 30 & 14,3 \\
Corrimento vaginal + prurido + odor fétido & 28 & 13,4 \\
Corrimento vaginal + dor pélvica & 11 & 5,2 \\
Corrimento vaginal + queixas vulvares & 7 & 3,4 \\
Total & 210 & \\
\hline
\end{tabular}


Após avaliação clínica e análise laboratorial da secreção vaginal colhida, observou-se que das 210 pacientes, 147 (70\%) apresentavam vulvovaginite inespecífica, da qual nenhum agente foi isolado, ao passo que em 63 (30\%) foi encontrado efetivamente um agente causal específico. Entre esses, o mais comum foi a presença de cocos sp observada em 26 casos, seguido pela cândida sp em 20, Gardnerella em 14, diplococos tipo neisseriformes em 2 e Trichomonas em 1 caso. Esses dados podem ser observados na Tabela 3 .

Tabela 3 - Agentes etiológicos observados na secreção vaginal colhida de 210 pacientes.

\begin{tabular}{lrc}
\hline Agente etiológico & $\mathbf{n}$ & $\%$ \\
\hline Alterações inflamatórias inespecíficas & 147 & 70,0 \\
Cocos sp & 26 & 12,4 \\
Cândida sp & 20 & 9,5 \\
Gardnerella vaginalis & 14 & 6,7 \\
Diplococos g-intracelulares & 2 & 0,9 \\
Trichomonas vaginalis & 1 & 0,5 \\
Total & 210 & \\
\hline
\end{tabular}

Das 210 pacientes avaliadas, $62(29,5 \%)$ tinham vida sexual ativa. A primeira relação sexual ocorreu aos 14,1 $\pm 1,6$ anos de idade, e $77,4 \%$ delas ( $\mathrm{n}=48$ ) não referiam uso de preservativos ou de qualquer outro método contraceptivo. Nove usavam preservativos e 5, anticoncepcionais orais, sendo 3 por orientação de amigas e 2 por farmacêutico. Quando relacionamos a análise da secreção vaginal com a atividade sexual dessas pacientes, observamos que os 14 casos de Gardnerella, 12 de cândida, 10 de cocos e 1 de Trichomonas foram encontrados em pacientes com vida sexual ativa e sem uso prévio de preservativos. Além disso, todos os casos de bartholinite, HPV e sifilis também foram encontrados nesse grupo de pacientes, como pode ser observado na Tabela 4.

Duas pacientes apresentaram, além da secreção vaginal abundante e esverdeada, bartholinite ao exame clínico. No entanto, a bacterioscopia da secreção vaginal foi inespecífica. Já em outras duas, sem bartholinite, mas com o corrimento vaginal com as mesmas características, observouse, à bacterioscopia, presença de diplococos gram negativos intracelulares tipo neisseriformes. Ambos os casos foram observados em meninas de 4 e 7 anos de idade. Não havia qualquer história de abuso sexual, sendo o exame realizado na presença dos pais, dentro da mais absoluta tranquilidade. Em 6 pacientes, a biópsia de lesão suspeita em região perineal confirmou o diagnóstico de HPV.
Tabela 4 - Agentes etiológicos observados na secreção vaginal das 62 pacientes com vida sexual ativa.

\begin{tabular}{lrc}
\hline Agente etiológico & $\mathbf{n}$ & \% \\
\hline Alterações inflamatórias inespecificas & 25 & 40,3 \\
$\quad$ \# bartholinite & $(1)$ & \\
\# HPV & $(1)$ & \\
Gardnerella vaginalis & 14 & 22,6 \\
$\quad$ \# Bartholinite & $(1)$ & \\
\# HPV & $(3)$ & \\
Cândida sp & 12 & 19,4 \\
Cocos sp & 10 & 16,1 \\
$\quad$ \# HPV & $(1)$ & \\
Trichomonas vaginalis & 1 & 1,6 \\
$\quad$ \# HPV & $(1)$ & \\
\# sífilis & $(1)$ & \\
Total & 62 & \\
\hline
\end{tabular}

\# Seis casos de HPV, 2 de bartholinite e 1 de sifilis foram observados concomitantemente nessas pacientes.

Vinte das 210 pacientes examinadas $(9,5 \%)$ apresentavam queixas vulvares concomitantes. Destas, o quadro mais freqüentemente observado foi o de prurido vulvar intenso, observado em 10/ 20 pacientes $(50 \%)$, sendo que em 5 observou-se verminose concomitante (oxiuriase), líquen escleroso em 4 e vitiligo vulvar em 1 , diagnosticados por biópsia de pele da região vulvoperineal. Quatro pacientes apresentavam sinéquia dos pequenos lábios $(20 \%)$, que foram desfeitas com o uso tópico e adequado de estrogênios conjugados; 3 (15\%) referiram sangramento genital, sendo que 1 sofrera trauma genital e 2 apresentavam pólipos himenais, que foram retirados, e $3(15 \%)$ pacientes queixavam-se de "carne crescida" na região vulvar, tendo sido observado ao exame, tratar-se da presença normal do himen em 1 paciente e do desenvolvimento adequado dos pequenos lábios em 2 . A análise da secreção vaginal colhida destas pacientes não revelou qualquer agente específico.

Em todos os casos avaliados, o enfoque terapêutico centrou-se na orientação dos hábitos de higiene e de vestuário, o que foi suficiente em todos os casos de secreção vaginal inespecífica e em $50 \%$ daqueles nos quais se encontrou flora cocóide ao exame. Quando se observou a presença de algum agente etiológico específico, infecção do trato urinário e/ou verminose concomitantes, estes foram adequadamente tratados, sem esquecer a orientação higiênica. No caso das queixas vulvares, motivo de muito mais apreensão dos pais do que o corrimento vaginal, tranquilização e uma explicação sobre a condição apresentada foi o suficiente. Todas as pacientes permanecem em seguimento ambulatorial, e aquelas com vida sexu- 
al ativa também foram orientadas quanto aos métodos contraceptivos e proteção contra DST.

\section{Discussão}

Em nosso estudo, 46,3\% (210/453) das pacientes, com idade inferior ou igual a 18 anos, que procuraram o AGIP/HUB no periodo de 2 anos referiram algum sinal e/ou sintoma vulvovaginal, sendo o corrimento a queixa mais freqüente. Brabin et al. ${ }^{7}$ e Koumantakis et al. ${ }^{8}$ observaram uma incidência de vulvovaginite de $82,4 \%$ e $61,8 \%$, respectivamente, em suas pacientes, na mesma faixa etária. Essa alta prevalência observada e o fato de Rau et al. ${ }^{5}$ terem afirmado, nos seus estudos, que a inflamação vulvovaginal é a queixa ginecológica mais comum na infância e adolescência, sendo responsável por $40-50 \%$ das consultas ao ginecologista, reforçam a importância que esta alteração clínica assume para as meninas e seus pais, e a importância que nós médicos temos na condução correta destes casos.

Os principais sintomas referidos pelas nossas pacientes, independente de sua idade e de atividade sexual, foram o corrimento vaginal, com ou sem odor fétido e o prurido semelhante ao relatado por Koumantakis et al. ${ }^{8}$. Esses sintomas devem ser analisados com cuidado antes de se prescreverem antibióticos ou cremes vaginais pois, como bem demonstraram De Campos et al. ${ }^{9}$, modificações inflamatórias são relativamente freqüentes em secreções vaginais. Contudo, apesar de a priori estas serem conseqüência de uma infecção genital, isso nem sempre é verdadeiro ${ }^{10}$, como bem pudemos observar em nosso estudo.

Como no trabalho de Jones $^{10}$, a vulvovaginite não-específica com flora bacteriana mista associada à higiene pós-miccional e principalmente anal deficitárias ou realizadas de forma incorreta, vestuário inadequado e, em crianças prépúberes, à presença de atrofia normal da mucosa vaginal, foi o tipo mais comum de vulvovaginite em nosso estudo, tanto em pacientes virgens como com vida sexual ativa. Não existe um consenso na literatura sobre o manejo dessas pacientes, nas quais uma etiologia bem definida está ausente ${ }^{9}$; no entanto, as 147 pacientes em que foram observadas alterações inflamatórias inespecíficas ao exame da secreção vaginal foram adequadamente tratadas com correção do vestuário e da higiene intima. Essa observação se reveste de especial importância pois, na ansiedade de resolver o problema prontamente, mesmo que de forma temporária, já que a paciente voltará a apresentar as mesmas queixas, muitos médicos, pediatras e gi- necologistas, esquecem as orientações fundamentais e prescrevem antibióticos e/ou cremes vaginais desnecessariamente.

As outras 63 pacientes, das quais um agente causal específico foi isolado, também receberam a mesma orientação quanto aos cuidados com higiene pessoal, conhecimento do próprio corpo, vestuário e hábitos, além do tratamento medicamentoso adequado. Vale ressaltar que nas pacientes das quais foram isoladas monília e flora cocóide e que não tinham atividade sexual, a orientação foi suficiente. No entanto, nas que mantinham relações sexuais foi necessário uso de medicação específica.

Em nosso trabalho, os agentes específicos mais comumente observados na secreção vaginal foram cocos sp, cândida sp e Gardnerella $(12,4 \%$, $9.5 \%$ e $6,7 \%$, respectivamente), semelhante ao observado por Koumantakis et $a .^{8}$ e por Maniatis et al. ${ }^{6}$. Contudo, quando analisamos somente as pacientes com vida sexual ativa, verificamos que a Gardnerella passa a ser o agente mais freqüente na secreção vaginal $(22,6 \%)$, seguido pela cândida sp $(19,4 \%)$ e pelos cocos sp $(16,1 \%)$, como relatado em vários outros trabalhos ${ }^{11-13}$, em que a vaginose bacteriana foi a causa mais comum de corrimento vaginal em mulheres sexualmente ativas.

Apesar da gardnerelose já ter sido observada em mulheres lésbicas ${ }^{14}$ e em adolescentes virgens ${ }^{15}$ sugerindo que este patógeno não seja de transmissão exclusivamente sexual, em nosso estudo todas as 14 pacientes com corrimento vaginal no qual esta bactéria foi encontrada referiam vida sexual ativa, sem uso de preservativos, tendo sido necessário medicação tópica e sistêmica para o tratamento efetivo destas pacientes, reforçando o estudo de Majeroni ${ }^{11}$, que atribui à Gardnerella vaginalis uma conotação sexual importante.

A queixa de corrimento vaginal e dor pélvica concomitante foi observada em 11 pacientes, todas com vida sexual ativa há mais de seis meses, das quais foram isolados patógenos específicos, tais como Trichomonas e Gardnerella. O fato de recentes estudos ${ }^{11,16}$ terem confirmado a associação entre doença inflamatória pélvica e presença de vaginose bacteriana ao exame ginecológico somente reforça a necessidade de tratamento antimicrobiano específico.

Quanto aos 2 casos em que foi observada a presença de diplococos gram negativos intracelulares tipo neisseriformes à bacterioscopia, não conseguimos caracterizar a infecção definitivamente. As crianças não tinham qualquer lesão ou alteração ao exame ginecológico, a não ser a presença de uma secreção vaginal espessa, amarelo- esverdeada sem odor. Também não foi obser- 
vado qualquer distúrbio de comportamento por parte das crianças ou de seus pais que nos levasse a suspeitar de abuso sexual. Além disso, poucas crianças são encaminhadas para avaliação mais detalhada de um possivel abuso baseado somente em sinais e sintomas apresentados ${ }^{17}$. Como não foi possivel a realização de cultura para confirmar o diagnóstico, não podemos afirmar com certeza de que se tratavam de casos de gonorréia. No entanto, vale ressaltar que somente após tratamento com antibióticos é que observamos cura nesses casos. As crianças continuam em seguimento ambulatorial e não voltaram a apresentar estas queixas.

Também vale ressaltar que 6 das 62 pacientes $(9,7 \%)$ com vida sexual ativa apresentaram HPV à biópsia genital, sendo que 1 destas meninas também apresentou sífilis e tricomoníase concomitantes. Apesar de 3 estarem em uso de anticoncepcionais orais por orientação de amigas, nenhuma usava preservativos. Com idades variando de 13 a 16 anos, todas haviam tido seu primeiro contato sexual entre 6 meses e 1 ano antes, e somente uma não estava no primeiro parceiro. Esses dados reforçam o estudo de Jamison et al. ${ }^{18}$, que afirma que o HPV é adquirido freqüentemente logo após o início da atividade sexual desprotegida, trazendo consigo a possibilidade de sérias conseqüências futuras para a paciente.

Em relação às queixas vulvares, motivo de muito mais angústia por parte dos familiares do que os quadros de corrimento vaginal, observamos que a conduta foi extremamente mais simples, passando sempre pela tranquilização dos pais e da paciente e do ensinamento do conhecimento do próprio corpo.

Dessa forma, podemos concluir que as alterações vulvares, quando adequadamente diagnosticadas, são facilmente conduzidas. Nas pacientes sem atividade sexual, os corrimentos vaginais, na maioria inespecíficos, são, quase sempre, adequadamente tratados com orientação higiênica e de vestuário, dispensando o uso de antimicrobianos. A Gardnerella, Trichomonas, HPV e sifilis foram observados somente em pacientes com vida sexual ativa, sendo a Gardnerella o patógeno mais freqüentemente obtido da secreção vaginal dessas pacientes. Além disso, o início precoce de atividade sexual (14,1 $\pm 1,6$ anos), observado em $29,5 \%$ das nossas pacientes de forma totalmente desinformada quanto à proteção contra DST e gravidez indesejada, sugere que os serviços de atenção primária à saúde deveriam estar melhor preparados para receber e orientar adequadamente estas meninas.

\section{SUMMARY}

Purpose: to assess the commonest vulvovaginal complaints and vaginal discharge etiology in the Child and Teenager Gynecologic Outpatient Clinic of the University Hospital of Brasilia (AGIP/HUB).

Methods: we evaluated retrospectively 210 charts of patients, younger than 19 years old, who attended AGIP/ $H U B$ with vulvovaginal complaints.

Results: the average age of the 210 patients was $12 \pm 2.3$ years, and the vaginal discharge and vulvar pruritus were the commonest complaints. Unspecific inflammatory conditions were observed in 147 (70\%) of these patients and their treatment consisted of appropriate clothing, daily activities and hygienic orientation. Antibiotic treatment was necessary in 63 patients, where specific etiologic agents were found. Gardnerella, Trichomonas, HPV and syphilis were observed only in sexually active patients. They had had their first sexual intercourse when they were $14.1 \pm 1.6$ years old. Twenty patients also presented vulvar complaints that were easy to handle.

Conclusion: Hygiene, clothing and adequate orientation for these patients and their families are fundamental to treat vulvovaginitis, almost always avoiding the use of antibiotics.

KEY WORDS: Childhood and adolescence. HPV. Vulvovaginits. Syphilis.

\section{Referências}

1. Cibley LJ, Cibley LJ. Cytolytic vaginosis. Am J Obstet Gynecol 1991; 165:1245-9.

2. Hill GB. The microbiology of bacterial vaginosis. Am J Obstet Gynecol 1993; 169:450-4.

3. Eschenbach DA, Davick PR, Williams BL, et al. Prevalence of hydrogen peroxide-producing Lactobacillus species in normal women and women with bacterial vaginosis. J Clin Microbiol 1989; 27:251-6.

4. Huggins GR, Preti G. Vaginal odors and secretions. Clin Obstet Gynecol 1981; 24:355- 77.

5. Rau FJ, Jones CE, Muram D. Vulvovaginite. In: Sanfilippo JS, Muram D, Lee PA, Dewhurst J, editores. Ginecologia Pediátrica e da Adolescente. $1^{\mathrm{a}}$ ed. Rio de Janeiro: Guanabara Koogan; 1996. p. 150-60.

6. Maniatis AN, Palermos J, Kantzanou M, Maniatis NA, Christodoulou C, Legakis NJ. Streptococcus agalactiae: a vaginal pathogen? J Med Microbiol 1996; 44:199-202. 
7. Brabin L, Kemp J, Obunge OK, et al. Reproductive tract infections and abortion among adolescent girls in rural Nigeria. Lancet 1995; 345:300-4.

8. Koumantakis EE, Hassan EA, Deligeoroglou EK, Creatsas GK. Vulvovaginitis during childhood and adolescence. J Pediatr Adolesc Gynecol 1997; 10:39-43.

9. De Campos DA, Nogueira A, Magalhães F, et al. Inflammatory smears in cervicovaginal cytology. A finding meaning infection? Acta Med Port 1997; 10:637-41.

10.Jones R. Childhood vulvovaginitis and vaginal discharge in general practice. Fam Prac 1996; 13:369-72.

11.Majeroni BA. Bacterial vaginosis: an update. Am Fam Physician 1998; 57:1285-9, 1291.

12.Nelson AL. The impact of contraceptive methods on the onset of symptomatic vulvovaginal candidiasis within the menstrual cycle. Am J Obstet Gynecol 1997; 176:1376-80.

13.Wathne B, Holst E, Hovelius B, Mardh PA. Vaginal discharge: comparison of clinical, laboratory and microbiological findings. Acta Obstet Gynecol Scand 1994; 73:802-8.
14.Skinner CJ, Stokes J, Kirlew Y, Kavanagh J, Forster GE. A case-controlled study of the sexual needs of lesbians. Genitourin Med 1996; 72:277-80.

15.Bump RC, Buesching WJ 3d. Bacterial vaginosis in virginal and sexually active adolescent females: Evidence against exclusive sexual transmission. Am J Obstet Gynecol 1988; 158:935-9.

16.Peipert JF, Montagno AB, Cooper AS, Sung CJ. Bacterial vaginosis as a risk factor for upper genital tract infection. Am J Obstet Gynecol 1997; 177:1184-7.

17.Kellogg ND, Parra JM, Menard S. Children with anogenital symptoms and signs referred for sexual abuse evaluations. Arch Pediatr Adolesc Med 1998; 152:634-41.

18.Jamison JH, Kaplan DW, Hamman R, Eagar R, Beach R, Douglas JM Jr. Spectrum of genital human papillomavirus infection in a female adolescent population. Sex Transm Dis 1995; 22:236- 43. 